\title{
Purchasing power parity in Asian economies: further evidence from rank tests for cointegration
}

\author{
Venus Khim-Sen Liew*, Hock-Ann Lee and Kian-Ping Lim \\ Labuan School of International Business and Finance, Universiti Malaysia \\ Sabah, Jalan Sungai Pagar, 87000 Labuan, Malaysia
}

The finding of nonlinear cointegration between Asian exchange rates with the corresponding relative prices and aggregate price levels based on Breitung's (2001) nonparametric rank tests reinforces previous validations of purchasing power parity (PPP) by the parametric testing procedures. Hence, the long-run Asian exchange rates are in equilibrium with the relevant fundamentals as suggested by the PPP hypothesis.

\section{Introduction}

Purchasing power parity (PPP) remains one of the most debated issues in international financial economics. ${ }^{1}$ The validity of PPP has various important implications to decision or policy makers of central banks, multinational firms and many other exchange rate market participants. In this respect, if the PPP holds, then one may evaluate whether an exchange rate is over- or under-valued based on the equilibrium value as suggested by PPP itself or the more complex monetary exchange rate models, in which PPP serves as the building block. Moreover, PPP and its extended models may also be adopted as reliable predicting tools for future exchange rate movements. An equally important implication of PPP study is that PPP reflects the degree of trade integration and liberalization among countries.

Previous empirical findings on the validity of PPP have been voluminous but puzzling (Rogoff, 1996). One of the reasons for the contrasting results as pointed out by recent studies is the negligence of nonlinear property of exchange rate behaviour. Principally, due to market frictions, heterogeneous agents and influence of official intervention in the foreign exchange market, exchange rate adjusts nonlinearly towards its PPP equilibrium value (Taylor, 2006). Empirically, Taylor (2001) and Kilian and Taylor (2003), amongst others, showed that the nonlinear adjustment of exchange rate towards PPP can best be described by exponential smooth transition autoregressive (ESTAR) model. ${ }^{2}$ Besides, Liew et al. (2003) demonstrated that linear autoregressive model is inadequate in characterizing the Asian (including ASEAN-5) real exchange rates behaviours. More recently, Liew et al. (2004a,b) further validated PPP in the nonlinear sense. Thus, it is reasonable for one to think that the puzzling results of PPP lies in the implicit linear assumption of exchange rate behaviour.

It is worth pointing out that the above nonlinear evidence adopts the parametric residual-based tests for cointegration approach to the testing of PPP hypothesis. This article differs from the others by

*Corresponding author. E-mail: venusliew@ums.edu.my

${ }^{1}$ Taylor $(2003,2006)$ and Taylor and Taylor (2004) provide in-depth overview on the conceptual, theoretical and empirical aspects of PPP.

${ }^{2}$ Teräsvirta (1994) provided theoretical details for ESTAR model. Also see Taylor (2006) for a concentrated discussion on the usefulness of this model in characterizing exchange rate adjustment. 